\title{
APLICAÇÃO DO AÇO AISI 430 COMO ELETRODO INDICADOR EM TITULAÇÃO POTENCIOMÉTRICA
}

\author{
M. R. T. SILVA' ${ }^{1}$, P. F. RIZZINI ${ }^{1}$, A. G. NASCIMENTO ${ }^{1}$, H. V. NASCIMENTO ${ }^{2}$, M. M. P. \\ SILVA* \\ ${ }^{1}$ Faculdade de São Bernardo do Campo, Departamento de Engenharia Química \\ ${ }^{2}$ Faculdade de São Bernardo do Campo, Departamento de Química \\ *E-mail para contato: mauricio.marques@fasb.com.br
}

\begin{abstract}
RESUMO - A titulação potenciométrica é um método analítico confiável pois é uma técnica mensurável que possui alta repetibilidade. Este procedimento analítico tem sido muito utilizado como alternativa a métodos que fazem uso de indicadores químicos a fim de auxiliar na produção da ciência com desenvolvimento sustentável. O presente trabalho mostra os estudos comparativos de uma titulação convencional que faz uso de indicador visual, com uma titulação potenciométrica que utiliza o aço inoxidável AISI 430 como eletrodo indicador. O eletrodo foi submetido a titulações de neutralização de ácido forte com base forte (ácido clorídrico e hidróxido de sódio) e seus resultados são expressos em gráficos que acompanham a variação de potenciais ao longo da análise. Da mesma forma, foi analisado o perfil gráfico da titulação potenciométrica com o eletrodo passivado em ácido nítrico $40 \%$ (v/v) e em ambas as condições o eletrodo apresentou resultados satisfatórios.
\end{abstract}

\section{INTRODUÇÃO}

A ciência, desde seus primórdios busca desenvolver materiais e métodos que auxiliem o ser humano no seu dia-a-dia. No início, não havia uma preocupação com resíduos gerados ou com o tempo gasto em uma análise. Contudo, com a industrialização o tempo passou a ser o diferencial nos processos e hoje, para a indústria, tempo é dinheiro. Mas ainda é necessário pensar que reduzir o tempo pode implicar na redução da qualidade. Então, o grande desafio das últimas décadas tem sido reduzir o tempo sem perder a qualidade, ou ainda, reduzir o tempo ganhando qualidade, que se faz o cenário ideal para qualquer processo. Tendo isto em mente foram surgindo eletrodos que pudessem acompanhar as transformações químicas e as variações de energia que ocorrem nas reações. Os eletrodos utilizados no segmento da eletroquímica podem ser divididos em dois grupos: eletrodos de referência e eletrodos indicadores (Harris, 2011).

Eletrodos de referência são os parâmetros dentro da célula eletroquímica para o eletrodo indicador: como o eletrodo de referência tem seu potencial conhecido e constante, é possível calcular o potencial de corrente que passa pelo eletrodo indicador. Os eletrodos de referência mais utilizados são os de hidrogênio, que possui potencial zero e por isso é base para todos os demais eletrodos; os de calomelano saturado (ECS), constituído por cloreto de mercúrio e cloreto de potássio, a $25^{\circ} \mathrm{C}$, com potencial de $0,242 \mathrm{~V}$ em relação ao eletrodo padrão de 


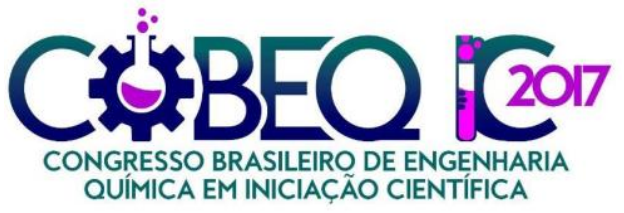

hidrogênio; e os de prata, constituídos por um fio de prata e solução de cloreto de prata, saturado a $25^{\circ} \mathrm{C}$, com potencial é de $0,222 \mathrm{~V}$. Os eletrodos indicadores por sua vez, possuem alteração no potencial de acordo com a concentração da solução em que estão imersos, conforme descrito por Rabockai (1977) e Higson (2009).

Segundo Higson (2009), a titulação potenciométrica, método utilizado neste trabalho, faz o uso de um eletrodo de referência e um indicador e é capaz de medir os potenciais de corrente conforme é dispensado o titulante sobre o titulado, pois a variação da concentração de íons em solução altera o potencial do eletrodo indicador.

Estudos recentes (Terra, et al., 2003; Carvalho, et al., 2011) mostram que o aço inoxidável já é aplicado em análises eletroanalíticas, e têm resultados satisfatórios, estudados por Terra (2004). Ainda são observados os comportamentos de eletrodos quimicamente modificados a fim de aproveitar mais a sua capacidade. A passivação do aço inoxidável é um destes métodos e se baseia na formação de um filme de óxidos na superfície do eletrodo. Este filme, apesar de frágil, diminui a velocidade de corrosão do aço, permitindo maior diversificação do emprego do aço como eletrodo indicador. Uma das formas de passivar o aço inoxidável é utilizar o ácido nítrico, conforme descrito nas normas da ASTM-A967-05.

$\mathrm{O}$ eletrodo indicador no presente trabalho foi desenvolvido com uma placa de aço inoxidável AISI 430, que faz parte da família dos ferríticos e é composto por cerca de $17 \%$ de cromo, $0,20 \%$ de titânio e $0,08 \%$ de carbono. Foi submetido a titulações potenciométricas com e sem passivação de ácido nítrico, tendo como referência o eletrodo de calomelano.

\section{OBJETIVOS}

Verificar a viabilidade do material como eletrodo indicador; avaliar o desempenho em relação ao meio submetido (ácido/básico) e com relação ao tratamento superficial (passivado e não passivado); e avaliar o desempenho relativo a titulação potenciométrica, quando comparado ao método tradicional por indicador químico (fenolftaleína), na determinação do ponto estequiométrico.

\section{METODOLOGIA}

As placas do aço AISI 430 foram lixadas para realização de limpeza superficial, utilizando lixas de 320, 400 e 600 mesh, respectivamente. Logo após, foram lavadas com água destilada e secas com ar quente. Delimitou-se, com uma fita autoadesiva, uma área de cerca de $4 \mathrm{~cm}^{2}$ para contato do eletrodo.

Para os ensaios com eletrodo quimicamente modificado (EQM), utilizou-se solução de ácido nítrico $40 \%$ v/v para a passivação do aço, que ocorreu durante 30 minutos. Após esse tempo, as placas foram retiradas da solução de ácido nítrico, e novamente lavadas com água destilada e secas com ar quente.

A titulação foi então realizada em duas condições diferentes: Titulante: $\mathrm{NaOH} 0,30$ mol. $\mathrm{L}^{-1}$ e Titulado: $\mathrm{HCl}$ 0,30 mol. $\mathrm{L}^{-1}$ ( $1^{\mathrm{a}}$ condição); Titulante: $\mathrm{HCl}$ 0,30 mol.L $\mathrm{L}^{-1}$ e Titulado: $\mathrm{NaOH} 0,30$ mol.L $\mathrm{L}^{-1}$ ( $2^{\mathrm{a}}$ condição).

O eletrodo indicador de aço inoxidável AISI 430 foi imerso, juntamente com o eletrodo de referência de calomelano, na solução de titulado na concentração 0,30 mol. $\mathrm{L}^{-1}$ sob agitação. Aguardou-se 20 minutos, para a estabilização do potenciais. Em seguida, iniciou-se a titulação com o titulante na mesma concentração de 0,30 mol. $\mathrm{L}^{-1}$. Fez-se a adição do titulante de $0,5 \mathrm{em}$ 
0,5 mL, aguardando-se a estabilização do potencial obtido por cerca de 1 minuto. Próximo ao ponto de equivalência a adição foi feita de $0,2 \mathrm{em} 0,2 \mathrm{~mL}$ aguardando cerca de 2 minutos para estabilização do potencial. Também realizou-se titulação com indicador de fenolftaleína para todas as condições estudadas, afim de se comparar os resultados obtidos. As análises foram realizadas em quadruplicata para atestar o comportamento observado.

\section{RESULTADOS E DISCUSSÕES}

Os resultados obtidos podem ser separados em dois grupos, meio inicial ácido e básico. Nesta separação, há então a comparação entre as placas sem e com tratamento superficial. Em todos os experimentos verificou-se que, na mesma condição, não houve variação no perfil gráfico da titulação e na primeira derivada.

\subsection{Titulação em Meio Básico}

Na placa não passivada, verifica-se o seguinte perfil expresso na Figura 1. Apesar das variações, na primeira derivada, pode-se verificar um ponto estequiométrico próximo ao obtido pelo método tradicional (aproximadamente 5,0 mL).

Figura 1 - Curva de titulação de solução NaOH 0,30 mol.L $\mathrm{L}^{-1}$ por HCl 0,30 mol.L $\mathrm{L}^{-1}$ com aço AISI 430 passivado como eletrodo indicador, seguido da primeira derivada.

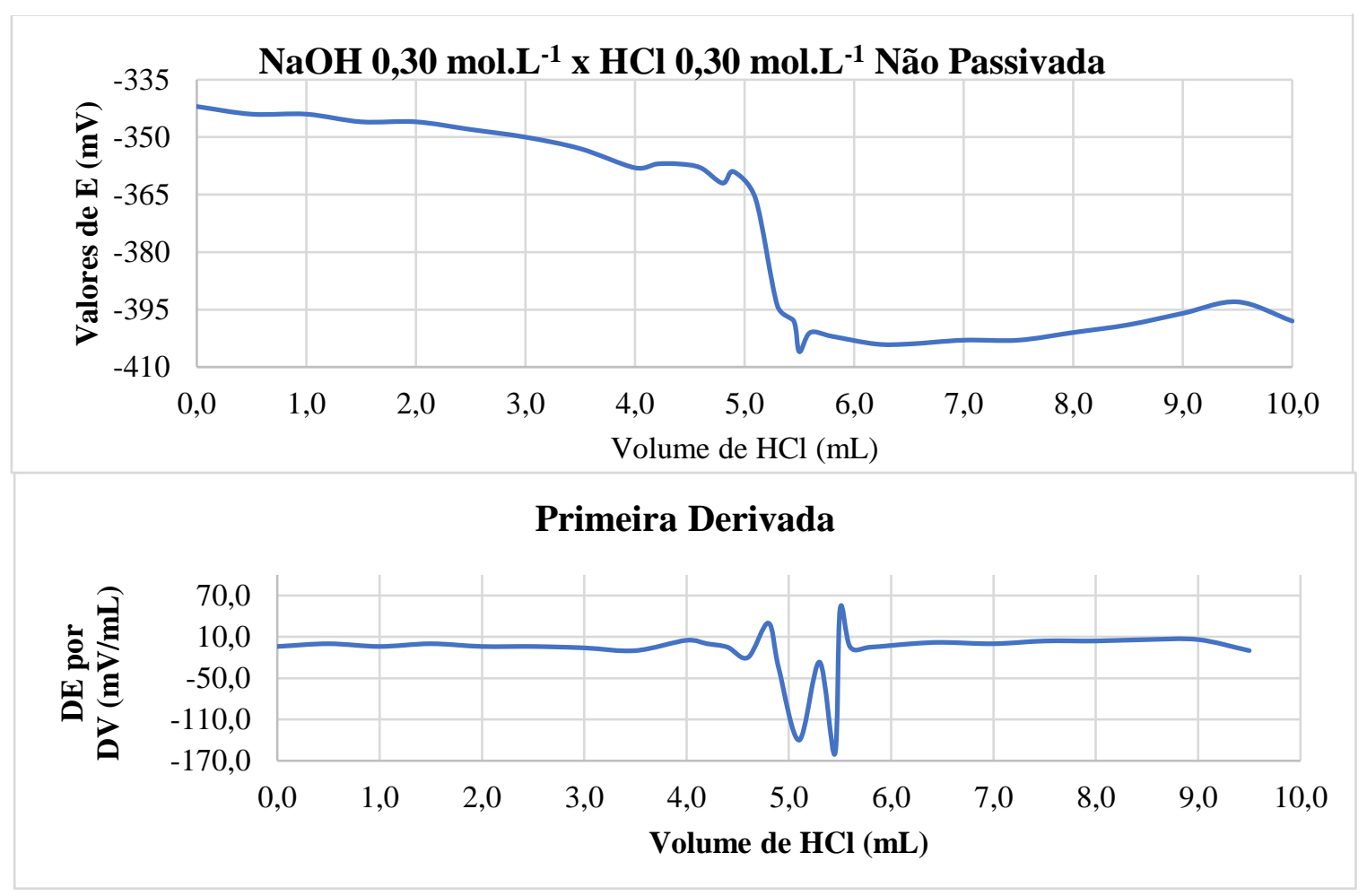

Para o mesmo meio, porém passivado, ou seja, com tratamento superficial, nota-se uma menor variação de potenciais, mostrada na Figura 2, permitindo assim um perfil mais próximo 
ao encontrado em literatura. Apesar das variações na primeira derivada, o resultado do ponto estequiométrico se fez em valor semelhante ao da titulação convencional (aproximadamente $5,0 \mathrm{~mL})$.

Figura 2 - Curva de titulação de solução NaOH 0,30 mol.L ${ }^{-1}$ por HCl 0,30 mol.L ${ }^{-1}$ com aço AISI 430 passivado como eletrodo indicador, seguido da primeira derivada.

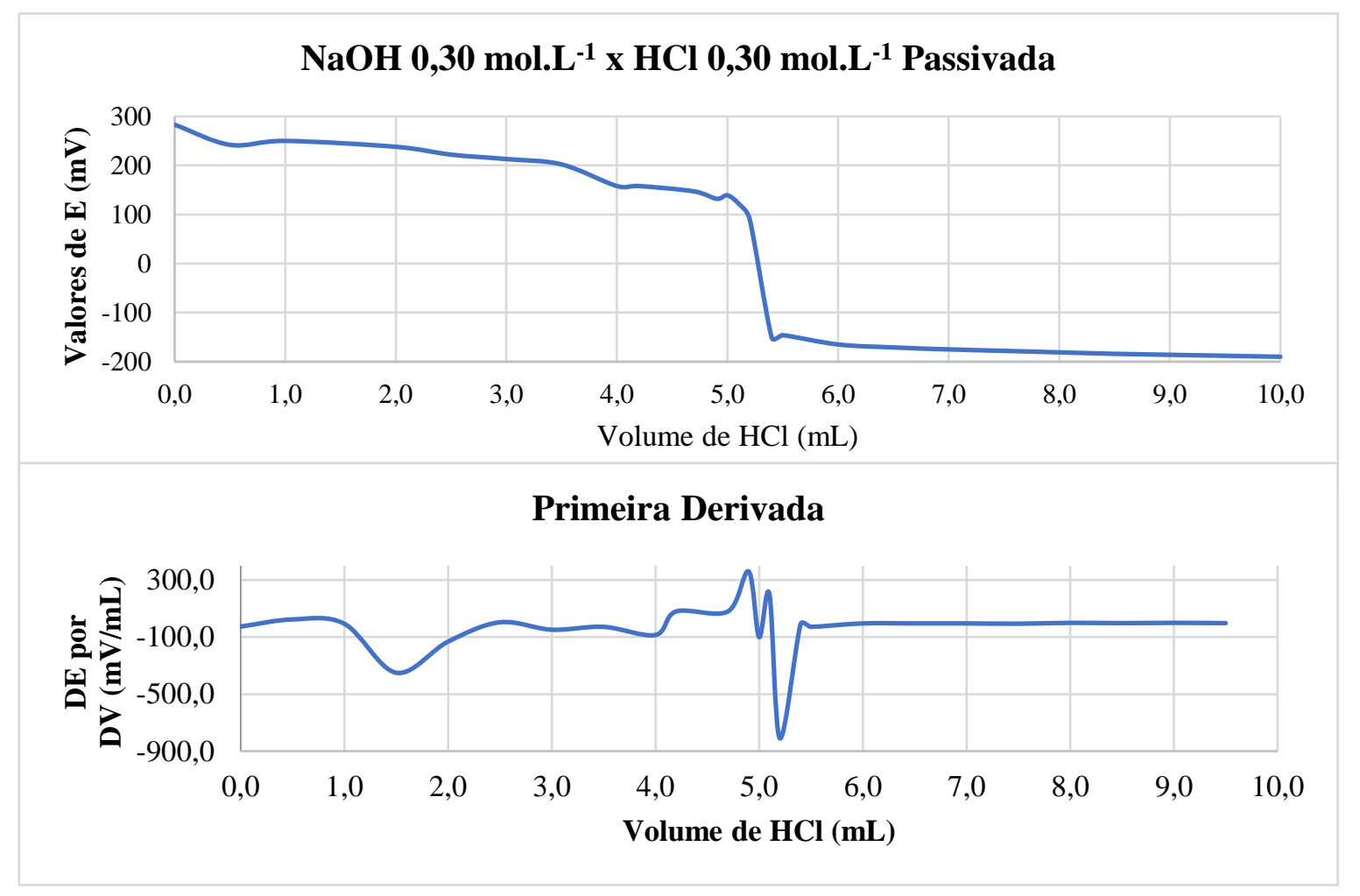

\subsection{Titulação em Meio Ácido}

O perfil exposto pela placa não passivada, Figura 3, não é convencional ao perfil da titulação potenciométrica; no entanto, o resultado obtido do ponto de equivalência foi próximo ao da titulação ácido x base realizada com indicadores (aproximadamente 5,0 mL). 
Figura 3 - Titulação de solução HCl 0,30 mol.L $\mathrm{L}^{-1}$ por NaOH 0,30 mol.L $\mathrm{N}^{-1} \mathrm{com}$ aço AISI 430 não passivado como eletrodo indicador, seguido da primeira derivada.

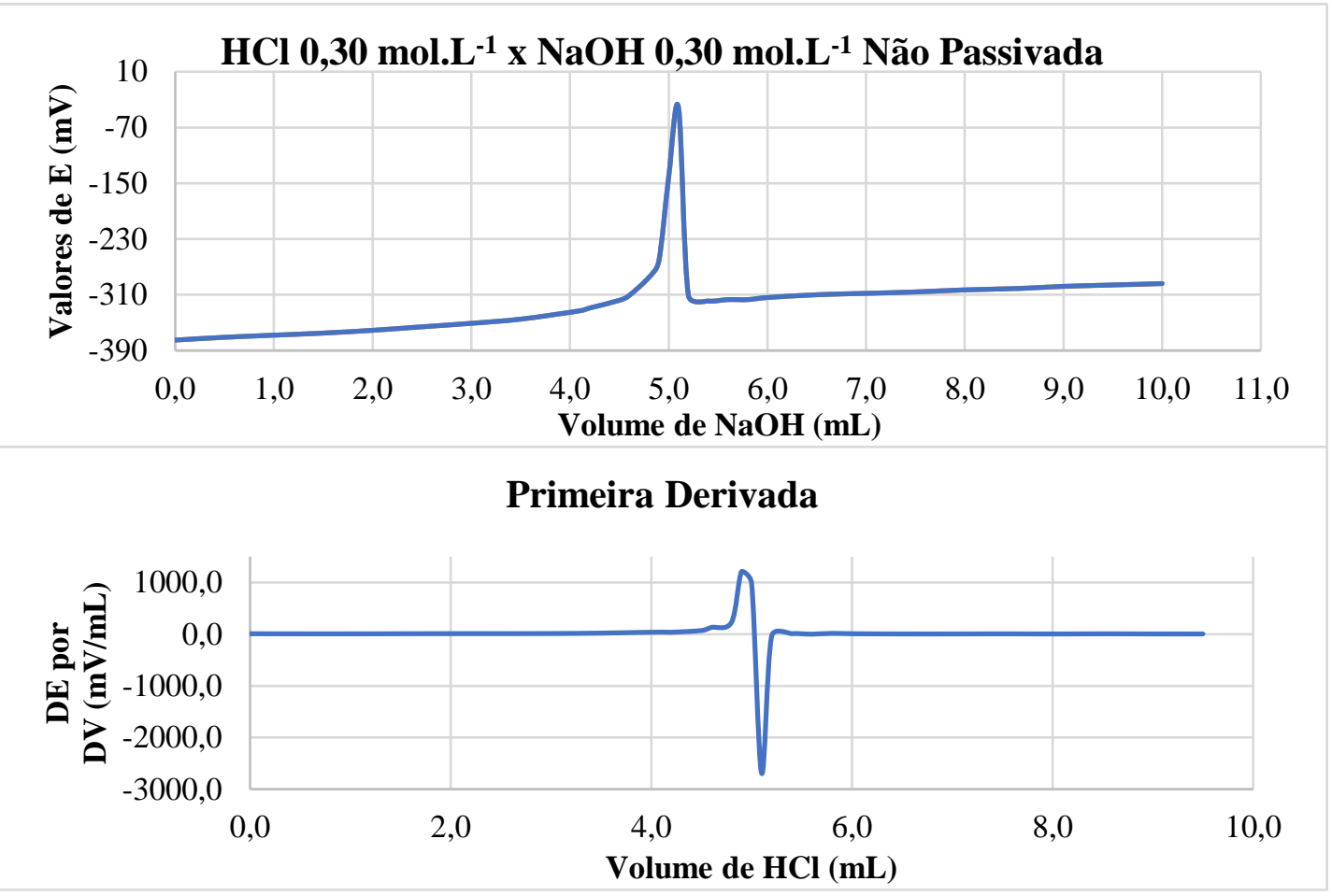

Na placa passivada o perfil gráfico, Figura 4, volta ao padrão com variações de potenciais no final do processo. Em sua primeira derivada, Figura 5, pode-se verificar facilmente o ponto estequiométrico equivalente ao encontrado na titulação tradicional (aproximadamente 5,0 mL).

Figura 4 - Titulação de solução HCl 0,30 mol.L ${ }^{-1}$ por NaOH 0,30 mol.L ${ }^{-1} \mathrm{com}$ aço AISI 430 passivado como eletrodo indicador, seguido da primeira derivada.

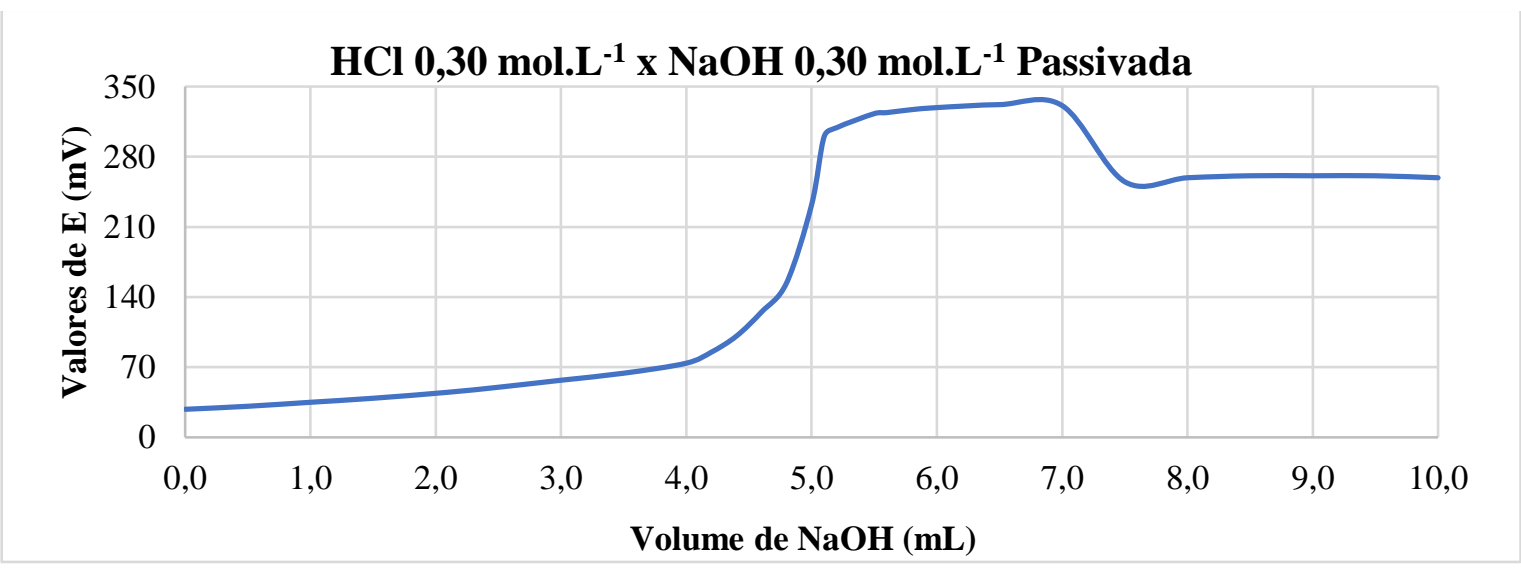


Figura 5 - $1^{\text {a }}$ derivada da titulação de solução $\mathrm{HCl} 0,30 \mathrm{~mol}^{-L^{-1}}$ por $\mathrm{NaOH} 0,30 \mathrm{~mol}^{-L^{-1}}$ com aço AISI 430 passivado como eletrodo indicador, seguido da primeira derivada.

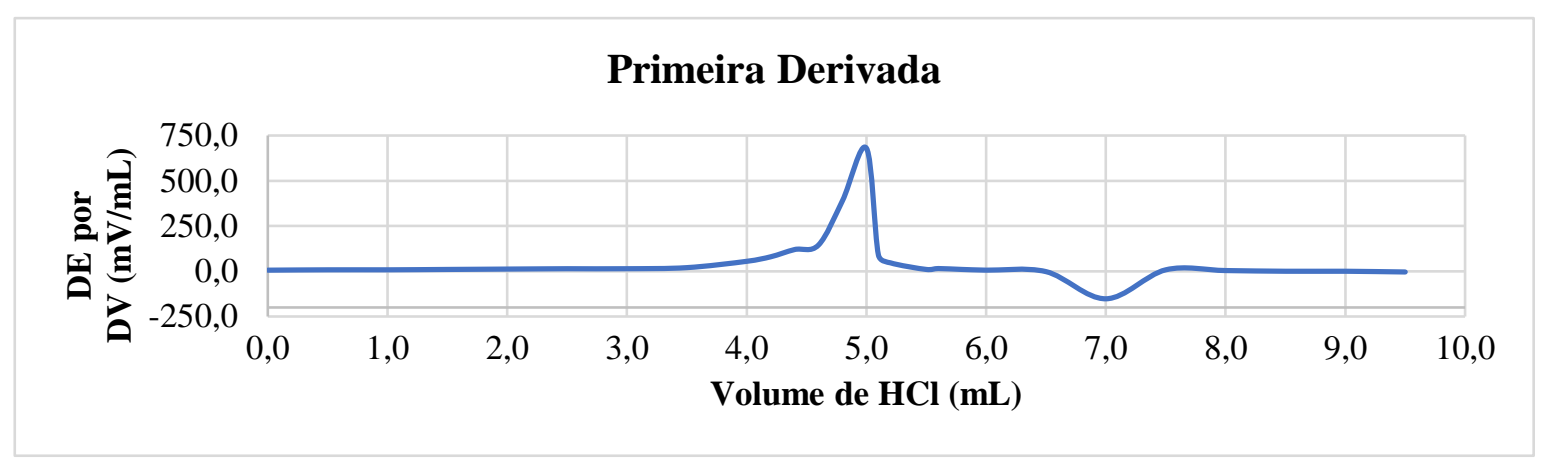

\section{CONSIDERAÇÕES FINAIS}

Os experimentos mostraram a possibilidade da utilização do aço inoxidável AISI 430 como eletrodo indicador em titulações potenciométrica, obtendo pontos de equivalência próximos aos das titulações convencionais. As condições que tiveram a curva de titulação mais próximas as encontradas em literatura foram as iniciadas em meio básico, apresentando menor variação de potenciais.

\section{REFERÊNCIAS}

AMERICAN SOCIETY FOR TESTING AND MATERIALS. A967 / A967M-13: Standard

Specification for Chemical Passivation Treatments for Stainless Steel Parts. West Conshohocken, 2007.

HARRIS, D. Explorando a química analítica. Ed. 4. Rio de Janeiro: Editora LTC, 2011. 550 p. HIGSON, S. Química analítica. Ed. 1. São Paulo: Editora McGraw-Hill, 2009. 452 p.

RABOCKAI, T. Eletroquímica: Iônica e Eletródica. ED. 2. São Paulo: Universidade de São Paulo, 1977. 102 p.

TERRA, L. H.; TORRES, N.; AGOSTINHO, S. M. L. Construção e Aplicação de Eletrodo de Aço Inoxidável UNS S31254 Como Eletrodo Indicador em Titulações Condutimétricas. Química Nova. São Paulo, n. 1, v. 26, p. 21-24, 2003.

CARVAlHO, B. R.; CUNHA, D. A.; UTCHUK, V. F. S.; AGOSTINHO, S. M. L.; SILVA, M. M. P. Titulação Potenciométrica Ácido-Base: Utilização do Aço AISI 304 Previamente Passivado Como Eletrodo Indicador. In: $34^{a} R A-S B Q, 2011$.

TERRA, L. H. Estudo do Aço Inoxidável Especial UNS S31254 Visando seu Emprego em Técnicas Eletroanalíticas. 2004. 131 f. Tese (Doutorado em Química) - Instituto de Química da Universidade de São Paulo, São Paulo, 2004. 